\title{
Interaction of phenol derivatives with ion channels
}

Phenols began to play a prominent role very early in modern operative medicine in the 1860s when Lister introduced his 'antisepsis' approach. The treatment of open wounds by carbolic acid dramatically reduced morbidity and mortality of surgical patients for the first time [1]. This central place in operative medicine was lost when, in the early 20th Century, 'asepsis' replaced 'antisepsis'. The powerful antibacterial properties of the phenols have resulted in their derivatives being widely used as stabilizers and preservatives in a huge variety of drug preparations, although this was hardly noticed by clinicians. Certainly, the phenol derivative best known by anaesthetists is propofol, a $\mathrm{GABA}_{\mathrm{A}}$ agonist and modulator which revolutionized intravenous anaesthesia. The purpose of this editorial is to present current knowledge of the structure-activity relation of phenol derivatives with respect to membrane spanning ion channels and receptors.

A substituted benzene ring is the common structural characteristic of a wide variety of pharmacologically active drugs, among them local anaesthetics $[2,3]$ and the general anaesthetic propofol $(2,6 \mathrm{di}$ isopropylphenol) (Fig. 1). Other structurally closely related phenol derivatives, such as 4-chloro-m-cresol, ben-zylalcohol and thymol, are in widespread use as bacteriostatic stabilizers in parenteral drug preparations. Naturally occurring phenolicmonoterpenes e.g. thymol, eugenol and carvacrol [4-8] are the active ingredients in the essential oils of plants occurring in the Mediterranean flora. Several beneficial effects have been ascribed to these essential oils, among others their strong bactericidal and antifungal activity [5,9-12] and their anti-inflammatory properties [4,13-15]. In addition, aromatic alcohols with intact phenolic groups and different phenol derivatives have been shown to act as scavengers of reactive oxygen species, thus protecting neurons effectively against oxidative damage and cell death [16].

Correspondence to: M. Leuwer, University Department of Anaesthesia, University Clinical Department, The Duncan Building, Daulby Street, Liverpool, L69 3GA, UK. E-mail: mleuwer@liv.ac.uk; Tel: +44 (0)151 706 4002; Fax: +44 (0)151706 5884

Accepted for publication October 2001 EJA 798
Although antinociceptive and local anaesthetic effects have long been described for benzylalcohol [17], eugenol and thymol [14], a possible molecular basis for these effects has only recently been

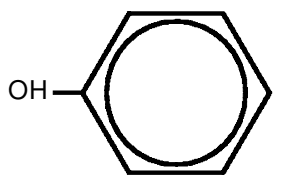

phenol

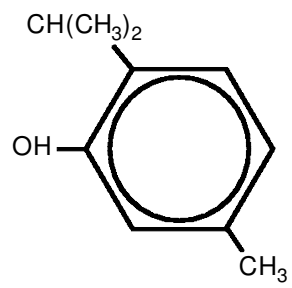

thymol

(5-methyl-2-isopropylphenol)

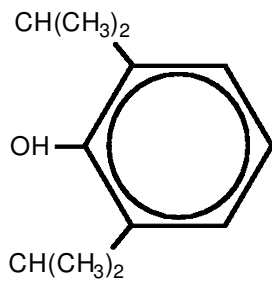

propofol

(2,6-diisopropylphenol)

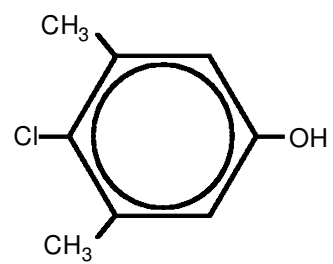

3,5-dimethyl-4-chlorophenol

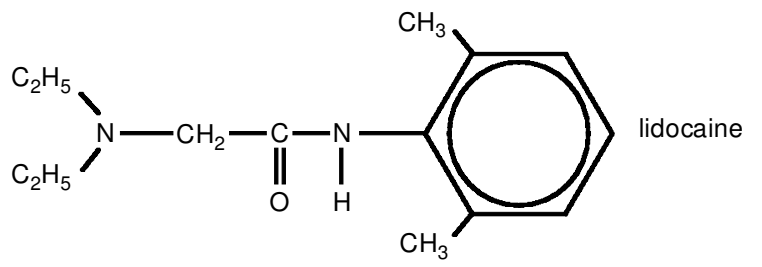

Figure 1.

Structures of some representative compounds containing a benzene ring with either a substituted (as in the case of local anaesthetics) or an unsubstituted (as in the case of the phenol derivatives) phenolic hyd roxyl g roup. 
elucidated. Phenol derivatives are potent blockers of heterologously expressed voltage-operated sodium channels in vitro. The addition of one to three substituents in the phenol molecule is sufficient to form compounds with equal or higher potency in blocking voltage-operated muscle sodium channels to lidocaine. For example, the $\mathrm{IC}_{50}$ value for lidocaine block of heterologously expressed muscle sodium channels at $-100 \mathrm{mV}$ was $500 \mu \mathrm{M}$ [18], compared with $150 \mu \mathrm{M}$ for 3,5-dimethyl-4-chlorophenol [19]. The blocking potency of phenol derivatives is increased by halogenation and by increasing the number of methyl groups. Substitution with longer aliphatic chains, as in the case of the anaesthetic propofol yields a compound with even higher blocking potency than 3,5-dimethyl-4-chlorophenol. Compounds with a methyl group attached directly to the benzene ring (e.g. 3-methylphenol) are more potent than compounds with a methyl group inserted between the ring and the phenolic hydroxyl group (benzylalcohol, [20]). The halogenated compound 4-chlorophenol is even more potent than the methylated compound (3-methylphenol). Insertion of methyl groups into the halogenated compound increased potency about two-fold with each methyl group; 4-chloro-2-methylphenol, in which the methyl group is attached at position 2 of the benzene ring, is slightly more potent than 4-chloro-3-methylphenol, in which the methyl group is attached at position 3 [21]. Thus, one can postulate that there are two important structural groups that confer reactivity on the molecule. Methyl groups, which partition in a hydrophobic pocket, are electron donors and most likely render the chloride at position 4 of the aromatic ring more electronegative [22]. Substitution of the methyl groups with a bulkier side-chain produces a more potent sodium channel blocker. In addition, the position of the methyl group (attached directly to the benzene ring or separating the benzene ring and the hydroxyl group), as well as halogenation in position 4 of the phenol ring, has a major effect on the acidity of the hydroxyl hydrogen and on the hydrogen bond donor vs. acceptor character of the molecule $[23,24]$.

These results make former structure-activity studies on the blocking potency of lidocaine-like local anaesthetics appear in a new light. The structural units that are characteristic of class I antidysrhythmic drugs and local anaesthetics are a hydrophobic aromatic group connected via an intermediate chain to a hydrophilic amine group [2]. In most of these drugs, the hydrophobic aromatic group is represented by a substituted phenol. Previous studies that have addressed the structure-activity relationship of the interaction of class $\mathrm{Ib}$ antidysrhythmic drugs with sodium channels have led to relatively few firm conclusions about precise structural contributions. An attempt to assess the structural determinants of lidocaine binding to sodium channels focused on homologues that differed in length between the arylamide and the amine domains of the molecule, or in the number of carbons attached to the terminal amine, but no structural changes were performed within the phenolic 'aromatic tail' of the molecule [25]. The approach of dissecting the lidocaine molecule into phenol and diethylamide provided first evidence for the assumption that the aromatic tail accounts for certain aspects of a lidocaine block, but did not take into account the fact that the aromatic group of the parent compound is a methylated phenol derivative [26]. Although phenol block mimicked slow block of cardiac sodium channels seen with lidocaine, blocking potency was an order of magnitude lower and skeletal muscle sodium channels were only minimally affected. Apparently, substituted phenol derivatives constitute a new group of sodium channel blocking agents. The potency of these compounds to block voltage-operated sodium channels is related to halogenation and to the size and position (with respect to the phenolic hydroxyl) of aliphatic substituents [19]. However, with the exception of propofol, most of the phenol derivatives studied are of experimental interest only at the present time and are in clinical use for applications other than the pharmacological blockade of sodium channels.

For the general anaesthetic propofol, several voltageoperated and ligand-gated ion channels have been described as possible target sites for its hypnotic [27-31] and muscle relaxant [32] effects. While propofol and local anaesthetics both block voltageoperated ion channels, they differ profoundly in their effects on the major receptor for inhibitory neurotransmission in the mammalian brain, the taminobutyric acid $\left(\mathrm{GABA}_{\mathrm{A}}\right)$ receptor. Local anaesthetics such as lidocaine, bupivacaine, procaine, benzocaine and cocaine have been shown to inhibit GABAinduced currents, a mechanism that might underlie the central nervous toxicity of local anaesthetics [33-35]. In contrast, propofol not only potentiates GABA-evoked currents, but also activates chloride currents through $\mathrm{GABA}_{\mathrm{A}}$ receptors in the absence of GABA [27,29,31,36-38]. Some experimental evidence suggests that this direct receptor activation in the absence of the agonist might determine the sedative-hypnotic as opposed to the anticonvulsant actions of propofol [38].

Studies on structurally closely related propofol analogues revealed that small structural changes within the molecule, i.e. halogenation, induce substantial changes in pharmacological profile and receptor kinetics [39]. While the potency of a phenol 
derivative to block voltage-operated sodium channels was higher in halogenated compounds [19], halogenation of the propofol molecule did not further increase its ability to directly activate $\mathrm{GABA}_{\mathrm{A}}$ receptors [39]. Animal experiments revealed that the halogenated propofol analogue showed anticonvulsant, but no sedative-hypnotic effects [38].

Which are the minimal structural requirements for a phenol derivative to activate $\mathrm{GABA}_{\mathrm{A}}$ receptors in the absence of the natural agonist? Structureactivity studies on direct agonist effects of different phenol derivatives revealed that only compounds with both the unsubstituted phenolic hydroxyl attached directly to the benzene ring and also a methyl or isopropyl group inserted in the ortho position to the phenolic hydroxyl group induce inward chloride currents via $\mathrm{GABA}_{\mathrm{A}}$ receptors. Potency was increased more than four-fold when a second methyl group was inserted in the ortho position, indicating that the ability of a phenolic compound to activate $\mathrm{GABA}_{\mathrm{A}}$ receptors is associated with 2,6 di-alkylsubstitution. The compound with only one isopropyl group in the ortho position (thymol) was slightly more potent than 2,6-dimethylphenol but propofol possessed the highest potency [40]. These findings might provide a molecular basis for the anaesthetic activity of ortho-alkylated phenol derivatives revealed by animal experiments, where the highest potency to induce sedation and sleep was associated with 2,6 di-alkyl-substitution [41].

Besides voltage-operated sodium channels and $\mathrm{GABA}_{\mathrm{A}}$ receptors, inhibitory glycine receptors have been described as possible target sites for propofol effects. GABA (gamma aminobutyric acid) is the most important inhibitory neurotransmitter in the brain, but glycine plays a major role in the spinal cord and lower brainstem [42]. The possible importance of these lower CNS areas and hence of glycine in general anaesthesia is emphasized by a decerebration experiment, which found the minimum alveolar concentration of isoflurane to be independent of cortical and forebrain structures in the rat $[42,43]$. Propofol, among other general anaesthetics, has been shown to potentiate the $\alpha_{1}$ glycine receptor in vitro [44] and to directly activate heterologously expressed glycine receptors in the absence of the natural agonist. It is conceivable that other phenol derivatives might equally interfere with glycine receptor function, but no evidence exists at the present time concerning structural requirements for this effect.

The in vitro effects described for propofol on the receptors for the major vertebrate excitatory neurotransmitter L-glutamate, are somewhat contradictory. Ionotropic glutamate receptor channels, which mediate fast excitatory transmission, can be classified according to their selective agonists: N-methyl-D-aspartate (NMDA), Kainate, and alphaamino-3-hydroxy-5-methyl-4-isoxazole propionate (AMPA) [42]. The dissociative agent ketamine exerts its effects largely by inhibiting the NMDA receptor [42], whereas the affinity of most other general anaesthetics for this receptor seems to be relatively low. Propofol on the one hand has been shown to produce a dose-dependent inhibition of whole-cell currents activated by NMDA in hippocampal neurons [45] and of currents through heterologously expressed NMDA receptors [46], but on the other hand to enhance NMDA-induced neuronal damage [47]. In addition, the convulsive potency of Kainate and AMPA in mice was enhanced by propofol [48]. The role of glutamate receptor modulation in general anaesthesia is controversial [42]; however, glutamate excitotoxicity has been implicated as an important cause of ischaemic, anoxic, epileptic and traumatic neuronal damage. Thus, further studies will be needed to elucidate a possible modulation of glutamate-induced excitotoxicity by propofol and other phenol derivatives.

Knowledge of differences in the interaction of drugs with channels and receptors at the molecular level has contributed to some understanding of differences in the pharmacological profile seen clinically. Consequently, structure-function analysis of drug effects at different channels and receptors may provide a basis for the design of drug s targeting different receptors with different potencies, translating into a desirable pattern of inhibitory or excitatory effects.

The use of virtually all local anaesthetics is limited due to central nervous toxicity occurring with higher brain concentrations. Local anaestheticinduced convulsions are especially attributed to the depression of inhibitory circuits in the central nervous system (CNS), among others the inhibition of GABA-induced chloride currents [33-35]. It is conceivable that ortho-alkylated phenol derivatives might represent an interesting alternative, as some compounds can be expected to combine sedativehypnotic and neuroprotective effects due to activation of inhibitory circuits in the CNS and radical scavenging properties [16] with lidocaine-like actions due to inhibition of voltage-operated sodium channels.

We should now consider the state-dependent interaction of phenol derivatives with voltageoperated sodium channels and comparison with the local anaesthetic lidocaine. Voltage-sensitive sodium channels are responsible for the increase in sodium permeability during the initial rapidly rising phase of the action potential in nerve, skeletal muscle, neuroendocrine, and heart cells. On depolarization, 
sodium permeability first increases dramatically and then decreases to the baseline level after approximately $1 \mathrm{~ms}$. This biphasic behaviour was described in terms of two experimentally separable processes that control sodium channel function: activation, which controls the rate and voltage-dependence of the sodium permeability increase following depolarization, and inactivation, which controls the rate and voltage-dependence of the subsequent return of sodium permeability to the resting level during a maintained depolarization. The sodium channel can therefore exist in three functionally distinct states: resting, active, and inactivated [49]. Both resting and inactivated states are nonconducting. The resting state is favoured by hyperpolarization of the membrane, the inactivated state is favoured by membrane depolarization. The increase in the fraction of inactivated with respect to resting channels on membrane depolarization, the so-called steady-state voltagedependence of inactivation, differs strongly between sodium channel isoforms from different tissues and between normal and mutant sodium channels. It has previously been shown that differences in the voltage-dependence of channel inactivation account for differences in sensitivity to sodium channel blocking agents with different binding affinities to resting with respect to inactivated channels between mutant and normal channels $[18,50]$ and between sodium channel isoforms from different tissues [51,52]. Thus, mutant as well as sodium channels damaged by hypoxia, may increase sensitivity to a blocking drug by changing the voltage-dependence of channel inactivation $[18,53]$.

Channels that have been inactivated are refractory unless the membrane is repolarized to allow them to return to the resting state, so-called recovery from inactivation [49].

The effect of the local anaesthetic lidocaine on voltage-operated sodium channels in different excitable tissues has been extensively studied. Lidocaineinduced sodium channel blockade is characterized by a higher affinity of the drug for inactivated channels compared with the resting state, and by prolonged recovery from inactivation, introducing a second, slow component representing drug dissociation from inactivated channels [18,54-57]. This prolonged recovery from inactivation, once lidocaine is bound, accounts for the consecutive decrease in sodium current relative to the first pulse during repetitive stimulation when the interpulse interval becomes too short to allow recovery from inactivated channel block.

Voltage-dependent block by all phenolic compounds retains a characteristic set of features that describes local anaesthetic block [18,54,55,57,58], but differs in the kinetics of drug binding and unbinding.
Similarly to local anaesthetics and antidysrhythmic drugs such as lidocaine, the blocking potency of all phenol derivatives strongly depends on the kinetic state of the channel, reducing the $\mathrm{IC}_{50}$ values more than three-fold when membrane depolarization before the test pulse induces channel inactivation. For all compounds examined, the dissociation constants from the fast-inactivated state of the channel, estimated from drug-induced shifts in the voltage-dependence of the availability curve [55], were about one order of magnitude lower than the dissociation constants from the resting state, assessed at hyperpolarized membrane potentials. This finding might be particularly important in pathological conditions, such as hypoxia or ischaemia, in which a normal resting membrane potential cannot be maintained, and the membrane is more depolarized [59].

For the anaesthetic propofol, these results might have direct consequences for its clinical use as a 'muscle relaxant'. At normal resting potentials of muscle $(-70 \mathrm{mV})$, significant blocking effects were only observed in the higher range of clinically relevant propofol concentrations $(1-10 \mu \mathrm{M}$ [60]). Affinity of the sodium channel for propofol was increased with membrane depolarization; the estimated dissociation constant of propofol from the inactivated state was $4.6 \mu \mathrm{M}$. Thus, in conditions where a normal muscle resting potential is maintained, a relevant degree of muscle relaxation due to blockade of muscle sodium channels should only be expected at relatively high tissue concentrations of propofol [32]. These results are consistent with a clinical study showing that spontaneous dystonic movements during induction of anaesthesia with propofol, attributed to a transient stimulation of deep brain structures, are reduced in magnitude and duration at higher induction doses of propofol $\left(5 \mathrm{mg} \mathrm{kg}^{-1}\right)$, though depth of anaesthesia monitored with the electroencephalograph (EEG) was equal. The authors postulated an additional, yet unexplained, 'muscle relaxing' effect achieved by higher tissue concentrations of propofol [61]. In pathological conditions, such as hypoxia, myotonia or ischaemia, in which the normal resting potential cannot be maintained, increasing the fraction of inactivated channels [59], sensitivity to propofol should be increased. Thus, under pathological conditions, relevant blocking effects of propofol are likely to occur at low propofol concentrations. This might explain the effectiveness of a relatively small propofol bolus $(50 \mathrm{mg})$ to reduce muscle tone and decrease spontaneous electromyograph (EMG) recording s in a patient with severe tetanus [62].

Analog ous to the effects described for other $\mathrm{Na}^{+}$ channel blocking drugs $[18,57]$, channel repriming 
after a depolarization is delayed by phenol derivatives [19]. This might, on the one hand, be due to drug-induced stabilization of the inactivated state. On the other hand, removal of inactivated channel block at $-100 \mathrm{mV}$ could slow down overall recovery processes studied by using a two-pulse protocol. Experiments with a conformational marker for the fast-inactivation gate have shown that lidocaineinduced slowing of sodium channel repriming does not result from a slowing of recovery of the fastinactivation gate [56]. If the same holds for phenol derivatives, recovery from fast inactivation would precede recovery of the ionic current in drug-bound channels. With the exception of benzylalcohol, the dissociation of all compounds from inactivated channels occurs on a time-scale that is hardly discernible from the time-course of recovery from fast inactivation. Thus this leads to a slight prolongation of the fast component of recovery and introduction of a second, slow component, of about $30 \mathrm{~ms}$ for all phenolic compounds [19,20]. Use-dependent block during repetitive stimulation in the presence of a channel blocking agent is generally observed when the time of membrane repolarization between the pulses is too short to allow recovery from inactivated channel block. The results on the kinetics of recovery from inactivated channel block explain the lack of use-dependent block at stimulating frequencies lower than $50 \mathrm{~Hz}$ seen with most phenolic compounds at concentrations below the $\mathrm{IC}_{50}$ for rest block. Lack of use-dependent blockade has equally been described for the structurally related local anaesthetic benzocaine [63]. In contrast, lidocaine induces substantial use-dependent block, even at lower stimulating frequencies [18]. Structure-activity studies of different local anaesthetics and their derivatives have shown that the rate of dissociation from inactivated channels, which determines the accumulation of frequency-dependent block during repetitive stimulation, is related primarily to the size of the aliphatic side-chains [63], the molecular weight, and charge [2]. Thus, the lack of frequencydependent block seen with compounds with single substituents at the phenol ring compared with lidocaine could be attributed to differences in molecular weight.

In conclusion, we can say that block of sodium channels by phenol derivatives apparently retains the principal features of local anaesthetic block described for lidocaine, although the kinetics of drug binding and unbinding are more than one order of magnitude faster.

Sodium channels and the outlook on possible clinical implications are now considered. Besides lidocaine-like actions, phenol derivatives uniformly tend to correct altered gating characteristics displayed by paramyotonia congenita mutant muscle sodium channels in vitro, accelerating impaired inactivation kinetics $[64,65]$. This effect could not be shown for lidocaine-like local anaesthetics [66], suggesting that the interaction of phenol derivatives with inactivation-deficient sodium channels might be more specific in this respect than the interaction of lidocaine with those channels. A wide variety of clinical conditions is characterized by the expression of sodium channels with altered inactivation characteristics as a result of hereditary defects, as in paramyotonia.

We turn to examine the interaction of phenol derivatives with inactivation-deficient congenita [59], or secondary damage, such as denervation [67], hypoxia or ischaemia $[53,68]$. Although the diseases differ in their origin and clinical picture, the subsequent alterations in channel gating are surprisingly uniform, comprising a delay in the time-course of channel inactivation which leads to altered membrane excitability. Thus, a possible direct interference of phenol derivatives with the impaired gating mechanism, which leads to a partial restoration of channel dysfunction to normal values, could become of clinical interest in those conditions.

This direct interference with altered gating characteristics, which was equally shown for the anaesthetic propofol in vitro, might have implications for the choice of the anaesthetic in myotonic patients. Life-threatening complications resulting from severe muscle rigidity during induction of anaesthesia have been observed using other anaesthetics in patients with hereditary sodium channel myopathies $[69,70]$. As myotonia in these cases is not responsive to neuromuscular junction blocking agents [71], the use of local anaesthetics is generally recommended for therapy or prevention of myotonic attacks $[59,72]$, including the management of myotonic contractions during surgical stimulation [71]. Propofol has lidocaine-like effects on mutant muscle sodium channels of paramyotonia congenita and, in addition, corrects altered inactivation phenotypes induced in vitro [64]. These results provide the molecular basis for the assumption that propofol might be effective in the prevention or treatment of perioperative and intraoperative muscle rigidity in patients with sodium channel myopathies. Unfortunately, prospective controlled clinical studies will be difficult to perform, because the incidence of the diseases is low, clinical signs as such may be nonspecific, and patients often refuse additional invasive testing. Thus, myotonia may be difficult to identify on routine preoperative examination by anaesthetists $[1,69]$. The in vitro results at least suggest that propofol may be the agent of choice for induction of anaesthesia in patients with known myotonia. 
Moreover, it should be regarded as a possible option for prevention or therapy of myotonic attacks.

\section{G. Haeseler \\ Department of Anaesthesia \\ Hannover Med ical School \\ Hannover, Germany \\ M. Leuwer \\ Department of Anaesthesia \\ The University of Liverpool \\ Liverpool, $U K$}

\section{References}

1. Lister $\mathrm{J}$. The antiseptic principle in surgical practice. Lancet 1867; 2: 353-356.

2. Ehring GR, Moyer JW, Hondeghem LM. Quantitative structure activity studies of antiarrhythmic properties in a series of lidocaine and procainamide derivatives. J Pharmacol Exp Ther 1988; 244: 479-492.

3. Glowka ML, Dargie RL, Codding PW. Spatial requirements of the $\mathrm{Na}$ channel binding site for class I antiarrhythmics as derived from the crystal structures of 4-substituted 2,6-bis (1-pyrrolidinylmethyl) phenols. J Med Chem 1991; 34: 2678-2684.

4. Lorente I, Ocete MA, Zarzuelo A, Cabo MM, Jimenez J. Bioactivity of the essential oil of Bupleurum fruticosum. J Nat Prod 1989; 52: 267-272.

5. Kulevanova S, Kaftandzieva A, Dimitrovska A, Stefkov G, Grdanoska T, Panovski N. Investigation of antimicrobial activity of essential oils of several Macedonian Thymus L. species (Lamiaceae). Boll Chim Farm 2000; 139: 276-280.

6. Pereira SI, Santos PA, Barroso JG, et al. Chemical polymorphism of the essential oils from populations of Thymus caespititius grown on the island S. Jorge (Azores). Phy tochemistry 2000; 55: 241-246.

7. Consentino S, Tuberosa CI, Pisano B, et al. In-vitro antimicrobial activity and chemical composition of Sardinian Thymus essential oils. Lett Appl Microbiol 1999; 29: 130-135.

8. Juliani HR Jr, Biurrun F, Koroch AR, Juliani HR, Zygadlo JA. Chemical constituents of the essential oil of Lippia laxibracteata (Verbenaceae). Planta Med 2000; 66: 567-568.

9. Evans JD, Martin SA. Effects of thymol on ruminal microorganisms. Curr Microbiol 2000; 41: 336-340.

10. Lambert RJ. Susceptibility testing: inoculum size dependency of inhibition using the Colworth MIC technique. J Appl Microbiol 2000; 89: 275-279.

11. Montes-Belmont R, Carvajal M. Control of Aspergillus flavus in maize with plant essential oils and their components. J Food Prot 1998; 61: 616-619.

12. Viollon C, Chaumont JP. Antifungal properties of essential oils and their main components upon Cryptococcus neoformans. Mycopathologia 1994; 128: 151-153.

13. Azuma Y, Ozasa N, Ueda Y, Takagi N. Pharmacological studies on the anti-inflammat ory action of phenolic compounds. J Dent Res 1986; 65: 53-56.
14. Anamura S, Dohi T, Shirakawa M, Okamoto H, Tsujimoto A. Effects of phenolic dental medicaments on prostaglandin synthesis by microsomes of bovine tooth pulp and rabbit kidney medulla. Arch Oral Biol 1988; 33: 555-560.

15. Yucel-Lindberg T, Twetman S, Skold-Larsson K, Modeer T. Effect of an antibacterial dental varnish on the levels of prostanoids, leukotriene B4, and interleukin-1 beta in gingival crevicular fluid. Acta Otontol Scand 1999; 57: 23-27.

16. Uhr M, Moosmann B, Behl C. Aromatic alcohols as neuroprotectants. J Neural Transm 1998; 54 (Suppl): 287-294.

17. Harper AA, Macdonald AG, Wann KT. The effect of temperature on the nerve-blocking action of benzyl alcohol on the squid giant axon. J Phy siol 1983; 338: 51-60.

18. Fan Z, George AL Jr, Kyle JW, Makielski JC. Two human paramyotonia congenita mutations have opposite effects on lidocaine block of $\mathrm{Na}^{+}$channels expressed in a mammalian cell line. J Phy siol 1996; 496 (Pt 1): 275-286.

19. Haeseler G, Piepenbrink A, Bufler J, et al. Structural requirements for voltage-dependent block of muscle sodium channels by phenol derivatives. Br J Pharmacol 2001; 132: 1916-1924.

20. Haeseler G, Mamarvar M, Bufler J, et al. Voltagedependent blockade of normal and mutant muscle sodium channels by benzylalcohol. Br J Pharmacol 2000; 130: 1321-1330.

21. Haeseler G, Leuwer M, Kavan J, Wurz A, Dengler R, Piepenbrock S. Voltage-dependent block of normal and mutant muscle sodium channels by 4-Chloro-m-Cresol. Br J Pharmacol 1999; 128: 1259-1267.

22. Zorzato F, Scutari E, Tegazzin V, Clementi E, Treves S. Chlorocresol: an activat or of ryanodine receptor-mediated $\mathrm{Ca}^{2+}$ release. Mol Pharmacol 1993; 44: 1192-1201.

23. Abraham MH, Chadha HS, Whiting GS, Mitchell RC. Hydrogen bonding. 32. An analysis of water-octanol and water-alkane partitioning and the delta log P parameter of seiler. J Pharm Sci 1994; 83: 1085-1100.

24. Elliott AA, Elliott JR. Voltage-dependent inhibition of RCK1 $\mathrm{K}^{+}$channels by phenol, p-cresol, and benzyl alcohol. Mol Pharmacol 1997; 51: 475-483.

25. Sheldon RS, Hill RJ, Taouis M, Wilson LM. Aminoalkyl structural requirements for interaction of lidocaine with the class I antiarrhythmic drug receptor on rat cardiac myocytes. Mol Pharmacol 1991; 39: 609-614.

26. Zamponi GW, French RJ. Dissecting lidocaine action: diethylamide and phenol mimic separate modes of lidocaine block of sodium channels from heart and skeletal muscle. Biophy s J 1993; 65: 2335-2347.

27. Belelli D, Callachan H, Hill-Venning C, Peters JA, Lambert JJ. Interaction of positive allosteric modulators with human and Drosophila recombinant GABA receptors expressed in Xenopus laevis oocytes. Br J Pharmacol 1996; 118: $563-576$.

28. Concas A, Santoro G, Serra M, Sanna E, Biggio G. Neurochemical action of the general anaesthetic propofol on the chloride ion channel coupled with GABAA receptors. Brain Res 1991; 542: 225-232.

29. Hales TG, Lambert JJ. The actions of propofol on inhibitory amino acid receptors of bovine adrenomedullary chromaffin cells and rodent central neurones. Br $J$ Pharmacol 1991; 104: 619-628. 
30. Rehberg B, Duch DS. Suppression of central nervous system sodium channels by propofol. Anesthesiology 1999; 91: 512-520.

31. Sanna E, Mascia MP, Klein RL, Whiting PJ, Biggio G, Harris RA. Actions of the general anesthetic propofol on recombinant human GABAA receptors: influence of receptor subunits. J Pharmacol Exp Ther 1995; 274: 353-360.

32. Haeseler G, Stormer M, Bufler J, et al. Propofol blocks human skeletal muscle sodium channels in a voltagedependent manner. Anesth Analg 2001; 92: 1192-1198.

33. Hara M, Kai Y, Ikemoto Y. Local anesthetics reduce the inhibitory neurotransmitter-induced current in dissociated hippocampal neurons of the rat. Eur J Pharmacol 1995; 283: 83-89.

34. Sugimoto M, Uchida I, Fukami S, Takenoshita M, Mashimo T, Yoshiya I. The alpha and gamma subunitdependent effects of local anesthetics on recombinant GABA(A) receptors. Eur J Pharmacol 2000; 401: 329-337.

35. Ye JH, Liu PL, Wu WH, McArdle JJ. Cocaine depresses GABAA current of hippocampal neurons. Brain Res 1997; 770: 169-175.

36. Sanna E, Garau F, Harris RA. Novel properties of homomeric beta 1 gamma-aminobutyric acid type A receptors: actions of the anesthetics propofol and pentobarbital. Mol Pharmacol 1995; 47: 213-217.

37. Sanna E, Mascia MP, Klein RL, Whiting PJ, Biggio G, Harris RA. Actions of the general anesthetic propofol on recombinant human GABAA receptors: influence of receptor subunits. J Pharmacol Exp Ther 1995; 274: 353-360.

38. Sanna E, Motzo C, Usala M, et al. Characterization of the electrophysiological and pharmacological effects of 4-iodo-2,6-diisopropylphenol, a propofol analogue devoid of sedative-anaesthetic properties. Br J Pharmacol 1999; 126: $1444-1454$.

39. Trapani G, Latrofa A, Franco M, et al. Propofol analogues. Synthesis, relationships between structure and affinity at GABAA receptor in rat brain, and differential electrophysiological profile at recombinant human GABAA receptors. J Med Chem 1998; 41: 1846-1854.

40. Mohammadi B, Haeseler G, Leuwer M, Dengler R, Krampfl K, Bufler J. Structural requirements of phenol derivatives for direct activation of chloride currents via GABA(A) receptors. Eur J Pharmacol 2001; 421: 85-91.

41. James R, Glen JB. Synthesis, biological evaluation, and preliminary structure-activity considerations of a series of alkylphenols as intravenous anesthetic agents. $J$ Med Chem 1975; 23: 1350-1357.

42. Franks NP, Lieb WR. Molecular and cellular mechanisms of general anaesthesia. Nature 1994; 367: 607-614.

43. Rampil IJ, Mason P, Singh H. Anesthetic potency (MAC) is independent of forebrain structures in the rat. Anesthesiology 1993; 78: 707-712.

44. Mascia MP, Machu TK, Harris RA. Enhancement of homomeric glycine receptor function by long-chain alcohols and anaesthetics. Br J Pharmacol 1996; 119: 1331-1336.

45. Orser BA, Bertlik M, Wang LY, MacDonald JF. Inhibition by propofol (2,6 di-isopropylphenol) of the N-methylD-aspartate subtype of glutamate receptor in cultured hippocampal neurones. Br $J$ Pharmacol 1995; 116: 1761-1768.
46. Yamakura T, Sakimura K, Shimoji K, Mishina M. Effects of propofol on various AMPA-, kainate- and NMDA-selective glutamate receptor channels expressed in Xenopus oocytes. Neurosci Lett 1995; 188: 187-190.

47. Zhu H, Cottrell JE, Kass IS. The effect of thiopental and propofol on NMDA- and AMPA-mediated glutamate excitotoxicity. Anesthesiology 1997; 87: 944-951.

48. Bansinath M, Shukla VK, Turndorf H. Propofol modulates the effects of chemoconvulsants acting at GABAergic, glycinergic, and glutamate receptor subtypes. Anesthesiology 1995; 83: 809-815.

49. Catterall WA. Cellular and molecular biology of voltagegated sodium channels. Physiol Rev 1992; 72 (Suppl 4): S15-S48.

50. Nuss HB, Kambouris NG, Marban E, Tomaselli GF, Balser JR. Isoform-specific lidocaine block of sodium channels explained by differences in gating. Biophys $J$ 2000; 78: 200-210.

51. Wright SN, Wang SY, Kallen RG, Wang GK. Differences in steady-state inactivation between $\mathrm{Na}$ channel isoforms affect local anesthetic binding affinity. Biophys J 1997; 73: 779-788.

52. Wright SN, Wang SY, Xiao YF, Wang GK. State-dependent cocaine block of sodium channel isoforms, chimeras, and channels coexpressed with the betal subunit. Biophys $J$ 1999; 76 (1 Pt 1): 233-245.

53. $\mathrm{Pu} \mathrm{J}$, Balser JR, Boyden PA. Lidocaine action on $\mathrm{Na}^{+}$ currents in ventricular myocytes from the epicardial border zone of the infarcted heart. Circ Res 1998; 83: $431-440$.

54. Balser JR, Nuss HB, Romashko DN, Marban E, Tomaselli GF. Functional consequences of lidocaine binding to slow-inactivated sodium channels. J Gen Physiol 1996; 107: 643-658.

55. Bean BP, Cohen CJ, Tsien RW. Lidocaine block of cardiac sodium channels. J Gen Phy siol 1983; 81: 613-642.

56. Vedantham V, Cannon SC. The position of the fastinactivation gate during lidocaine block of voltage-gated $\mathrm{Na}^{+}$channels. J Gen Phy siol 1999; 113: 7-16.

57. Scheuer T. Commentary: A revised view of local anesthetic action: what channel state is really stabilized? J Gen Phy siol 1999; 113: 3-6.

58. Balser JR, Nuss HB, Orias DW, et al. Local anesthetics as effectors of allosteric gating. Lidocaine effects on inactivation-deficient rat skeletal muscle $\mathrm{Na}$ channels. J Clin Invest 1996; 98: 2874-2886.

59. Lehmann-Horn F, Rudel R. Hereditary nondystrophic myotonias and periodic paralyses. Curr Opin Neurol 1995; 8: 402-410.

60. Tonner PH, Poppers DM, Miller KW. The general anesthetic potency of propofol and its dependence on hydrostatic pressure. Anesthesiology 1992; 77: 926-931.

61. Borgeat A, Dessibourg C, Popovic V, Meier D, Blanchard M, Schwander D. Propofol and spontaneous movements: an EEG study. Anesthesiology 1991; 74: 24-27.

62. Borgeat A, Dessibourg C, Rochani M, Suter PM. Sedation by propofol in tetanus - is it a muscular relaxant? Intensive Care Med 1991; 17: 427-429.

63. Quan C, Mok WM, Wang GK. Use-dependent inhibition of $\mathrm{Na}^{+}$currents by benzocaine homologs. Biophys J 1996; 70: 194-201. 
64. Haeseler G, Stormer M, Mohammadi B, et al. The anesthetic propofol modulates gating in paramyotonia congenita mutant muscle sodium channels. Muscle Nerve 2001; 24: 736-743.

65. Haeseler G, Piepenbrink A, Bufler J, et al. Phenol derivatives accelerate inactivation kinetics in one inactivationdeficient mutant human skeletal muscle $\mathrm{Na}(+)$ channel. Eur J Pharmacol 2001; 416: 11-18.

66. Sah RL, Tsushima RG, Backx PH. Effects of local anesthetics on $\mathrm{Na}^{+}$channels containing the equine hyperkalemic periodic paralysis mutation. Am J Physiol 1998; 275 (2 Pt 1): C389-C400.

67. Marban E, Yamagishi T, Tomaselli GF. Structure and function of voltage-gated sodium channels. J Physiol 1998; 508 (Pt 3): 647-657.

68. Ashton D, Willems R, Wynants J, Van Reempts J, Marrannes R, Clincke G. Altered $\mathrm{Na}(+)$-channel function as an in vitro model of the ischemic penumbra: action of lubeluzole and other neuroprotective drugs. Brain Res 1997; 745: 210-221.

69. Neuman GG, Kopman AF. Dyskalemic periodic paralysis and myotonia. Anesth Analg 1993; 76: 426-428.

70. Vita GM, Olckers A, Jedlicka AE, et al. Masseter muscle rigidity associated with glycine1306-to-alanine mutation in the adult muscle sodium channel alpha-subunit gene. Anesthesiology 1995; 82: 1097-1103.

71. Russell SH, Hirsch NP. Anaesthesia and myotonia. Br J Anaesth 1994; 72: 210-216.

72. Munsat TL. Therapy of myotonia. A double-blind evaluation of diphenylhydantoin, procainamide, and placebo. Neurology 1967; 4: 359-367. 